\title{
THE IMPORTANCE OF REFLECTION-BASED STRATEGIES IN TRAINING PROFESSIONALS WORKING WITH MDVI CHILDREN
}

\author{
Andrea Hathazi, \& Ioana-Letitia Serban \\ Department of Special Education, Babes-Bolyai University (Romania)
}

\begin{abstract}
This paper focuses on the professional development regarding communication abilities of the teachers and therapists working with children with multiple disabilities and a visual impairment (MDVI). Since the development of communication abilities is a complex process, it must be approached from a continuous, systemic and structured perspective. MDVI children acquire and develop communication skills based on various factors which depend on their specific features and usually they need a large amount of time to learn how to employ different systems of communication so they can express a need or a desire and have an impact on other people or on the environment.

In this context, a team of 3 universities, 4 special schools for the blind and visual impaired, one NGO and one IT company have come together in an Erasmus+ European project called PrECIVIM (Promoting Effective Communication for Individuals with a Vision Impairment and Multiple Disabilities) to address the need of a professional training in communication abilities of the specialists working with MDVI children. As a result, a complex training program has been created, based on common experiences, reflective strategies, and different training components.

Method: We have focused on a group of 21 professionals working with MDVI children. They were the beneficiaries of a four-part training programme conducted by three experienced trainers on a time frame of 6 months. The programme was delivered in multiple ways, each of them with great reflective value: training manual (individual study), onsite group training, online group supervision and written individual reflective logs.

Results: The individual feedback of each participant has been processed and discussed revealing significant improvement in their intervention approach toward MDVI children, in their selection of communication methods or in their professional relationship with the MDVI child. The results of the training programme are presented in terms of the efficiency of the reflection-based strategies for the professional development of each participant.

Conclusion: The training programme applied to this group of professionals has emphasized the need of mentors and partners who offer constructive feedback and who implement reflective strategies in the intervention process regarding communication with MDVI children. In this sense, the reflective logs should be considered a great resource in the intervention and therapeutic process of MDVI children.
\end{abstract}

Keywords: Teacher training, MDVI, reflection-based strategies.

\section{Theoretical background}

Reflective writing is meant to support a professional in developing a deep learning style, by understanding the process rather than memorising facts (Powell et al., 2017) and it is used to improve professional decision making. It addresses the idea of looking back to own activity and writing down the steps of the actions. In this view the specialist will easily and immediately gain a perspective of strategies and a personal feedback. So, while a participant is writing back his/her activity our goal was to guide $\mathrm{him} /$ her to constantly observe and analyse the process (alternatives which may come to mind, different angles of interpretation of a behaviour or of an intention on communication from the MDVI child). Reflective thinking addresses relating, experimenting, exploring, and connecting theory and practice (McCarthy, 2011; Helyer, 2015). Effective professional development is an on-going process which includes training, practice and feedback, provides sufficient time for the trainee to deepen their knowledge, but also allows follow-up support (Darling-Hammond et al., 2017). When engaging in a professional development programme, the specialists working with MDVI children should develop different sets of skills to support the evaluation and the intervention regarding the communication process. Among the professional responsibilities highlighted by a training programme the participants should find: making a reflection about 
teaching, creating their own documents and resources adapted to the needs of the MDVI child, communication strategies with the child's family, engaging in the professional community and general professional development (Rudiyati et al., 2019). Even though reflective practices are always encouraged, sometimes the trainer must select a range of different techniques and strategies that teach the reflection process itself, for there are professionals who are not prepared to reflect or have never done it (Kreber \& Castleden 2009, Coulson et al., 2013).

\section{Method}

The present research included a group of 21 professionals working with MDVI children. They were the beneficiaries of a four-part training programme conducted by three experienced trainers from a Romanian university on a time frame of 6 months. The programme was delivered in multiple ways, each of them with great reflective value: a training manual for individual study, an onsite group training, online group supervision sessions and written individual reflective logs delivered by e-mail. The participants' profile was as follows: 17 women and 4 men; 13 professionals with an experience between $0-5$ years and 8 professionals with 6 to 10 years of experience; 7 participants were special education teachers, 4 occupational therapists, 3 caregivers, 3 psychologists, 2 educators and 2 speech and language therapists.

\section{Procedure}

The first component of the programme that has been delivered to the participants was the training manual - meant for individual study and reflection. The second component was the onsite group training. This has been delivered by one of the university experts in a modular way on a 3-days session. The next component was the presentation of the reflective logs. They were delivered individually via e-mail to all the participants of the onsite training. The reflective logs consisted in the presentation of a case study.

Each case study had to be described in the reflective log in terms of: the communication profile of the beneficiary, the preparation steps for the intervention plan (assessment tools, materials, long and short-term objectives, strategies and techniques), the description of the intervention (strategies, resources, challenges), reflection on the observation techniques that they have used during the intervention and finally a self-reflection section (challenges, progress, feelings about the relationship with the beneficiary, improved aspects in their strategies, etc.). The reflective logs were completed by the participants and sent to two university trainers who then provided individual feedback on each case. During a 6-month period, the participants have each completed between 3 and 4 reflective logs. The fourth training component consisted of the online group supervision sessions. They were introduced after the participants started to get familiar with the reflection logs and aimed two objectives: (a) to follow the way the information from the manual and the onsite training was used in the reflective logs tasks and (b) to give an opportunity to the participants to share their experiences, challenges, outcomes, successes with the other participants in the group while also receiving group-feedback and feedback from the expert. The trainer of the online group sessions was the same one who conducted the onsite training session.

\section{Results}

We are going to discuss the results of the reflection-based strategies in our training programme by the analysis of the reflective logs. We considered these reflective logs as the most insightful instrument of professional growth because it contributed to the development of the participants' reflective skills and it gained value as it was supported by a strong feedback on the intensity of reflection that they have achieved. According to some studies (Bain et al., 2002, Coulson et al., 2013) the feedback given by the mentor to their trainee should also be combined with issue-related questions which challenge critical thinking.

The reflective logs were the final component of the training programme and in this section, we are going to present what a reflective perspective focuses on in this type of individual assessment and supervision tool. As previously stated, the reflective logs were an individual written task comprised of an analysis of a current working case that the specialist decided to share with his/her mentor and supervisor via e-mail. These reflective logs were used in the Erasmus+ PrECIVIM project as an individual evaluation and supervision tool. At the end of the 6-month period, many of the participants have already made new intervention plans or had a new or better vision on how to improve their intervention, their relationship with the MDVI child, and so on, as illustrated in Table 1. The reflective logs gave participants the possibility to reflect on their own intervention by acknowledging the objectives they have achieved, stating how they managed challenging behaviours, recognising, and naming their feelings about the intervention and finally revealing what has changed in their professional development (relationship with the child, a better 
understanding of the child, higher acceptance/ tolerance of the child's opinions, and so on). The reflective logs had a very important component: the feedback section completed by the mentor. The feedback allowed the specialists to reflect further by comparing it to their own thoughts as well as to the opinions of the other team members. All the interventions have been improved during the 6 months of the unfolding of the reflective logs and the contribution of these reflective logs to the personal growth of each professional was undeniable and the final comments of each one of them is proof to that statement. Reflective logs require describing experiences and critically reassessing the activities, thus achieving a higher level of understanding (Powell et al., 2017; Walker et al., 2013; Urdang, 2010). This kind of individual process has ensured for the participants the specific significance of the communication development in the context of MDVI children where the diversity of the needs and abilities is so great.

Table 1. Participants reflections about self-development as registered in the reflection logs (RL).

\begin{tabular}{|l|c|c|c|c|}
\hline \multicolumn{1}{|c|}{ Type of reflection } & $\begin{array}{c}\text { Participants } \\
\text { responding in } \\
\text { RL 1* } \\
\text { Total N=21 }\end{array}$ & $\begin{array}{c}\text { Participants } \\
\text { responding in } \\
\text { RL 2** } \\
\text { Total N=21 }\end{array}$ & $\begin{array}{c}\text { Participants } \\
\text { responding } \\
\text { in RL 3*** } \\
\text { Total N=21 }\end{array}$ & $\begin{array}{c}\text { Gain } \\
\text { indicator**** } \\
\text { at the end of } \\
\text { the } \\
\text { programme }\end{array}$ \\
\hline $\begin{array}{l}\text { I will use the reflecting log } \\
\text { as a tool for recording data } \\
\text { and building teamwork }\end{array}$ & 3 & 9 & 12 & 3 \\
\hline $\begin{array}{l}\text { I feel much more } \\
\text { confident and secure about } \\
\text { my intervention }\end{array}$ & 10 & 11 & 13 & 0,3 \\
\hline $\begin{array}{l}\text { I feel that my intervention } \\
\text { is now more appropriate } \\
\text { and focused }\end{array}$ & 16 & 16 & & 0 \\
\hline $\begin{array}{l}\text { I feel much more tolerance } \\
\text { and/ or acceptance toward } \\
\text { the MDVI child I am } \\
\text { working with }\end{array}$ & 5 & 8 & 9 & 0,8 \\
\hline $\begin{array}{l}\text { I feel that the relationship } \\
\text { between me and the } \\
\text { MDVI child has been } \\
\text { improved }\end{array}$ & 3 & 10 & 11 & \\
\hline
\end{tabular}

*RL 1 (reflective log no. 1) has been completed after 2 months of the training programme.

**RL 2 has been completed after 4 months of the training programme.

$* * *$ RL 3 has been completed after 6 months of the training programme.

$*_{* * *}$ The gain indicator measures the profit of self-development regarding a certain type of reflection from the first reflective log to the last one. The formula for the gain indicator is:

(P3/P1) - 1; where P3 represents the number of participants acknowledging that type of reflection in the RL3 and P1 represents the number of participants acknowledging that type of reflection in the RL1.

\section{Discussion}

As presented in Table 1, there were some immediate benefits after the first two components of the training programme (the manual and the onsite training) in terms of adjusting the intervention to the needs of the MDVI child. 16 out of 21 specialists have stated that studying the training manual, acknowledging the specific communication strategies, planning the intervention and observing their relationship with the MDVI child as he/she is making steps toward the short-term objectives have given the professionals the feeling that their intervention is now more appropriate and focused. This type of reflection was written in the logs in multiple ways as this self-reflection question was asked in an open manner: How do you feel about what you have learnt? How do you intend to use the data which occurred from the action and observation phase in order to improve or move on to your next interventions? Some examples of the responses which were registered under the tag: I feel that my intervention is now more appropriate and focused are presented in Table 2. 
Table 2. Participants responses on self-reflection analysis of their intervention.

The intervention helped me to proceed with my objectives for the student. The communication diaries were used in a more systematic way.

This procedure reminded me that we should have small and clear objectives each time.

I'll use the data to improve the intervention in order for him to communicate better with his environment.

I feel that I need to be prepared to re-think an activity and practice it tirelessly with the student. I think this procedure is really helpful in that manner.

The data we gather will be used to determine whether our intervention is successful and what has to be corrected, so that the results will be the best possible.

This data will help to improve the design of the next interventions since it will be easier to assess the level of communication of the student. So, the choice of the intervention methodology will also be more appropriate and focused.

I feel it helps me become more structured and organized.

This type of reflection was constant in all three important steps of the reflection logs which means that our training programme has reached its objective in terms of identifying and observing the use of the communication strategies needed for each specific MDVI case.

A second type of reflection which also had a constant presence in all the 3 steps of the reflective logs was: I feel much more confident and secure about my intervention. This was a very positive and encouraging feedback for our training programme. Some of the answers in the reflective logs that were registered in this category are presented below in Table 3 :

Table 3. Participants responses regarding confidence with their interventions.

\begin{tabular}{|l|}
\hline The information, the suggestion and the methodology proposed make me feel safer about my decisions. \\
\hline I feel more prepared to interact with the student \\
\hline I feel more prepared and flexible to change \\
\hline I feel confident and think I can continue with my next objective \\
\hline I am very satisfied \\
\hline I feel more confident and thankful for this training trip \\
\hline $\begin{array}{l}\text { I feel prepared and safe to interact with the student but I am always alert that her reactions may be unsafe } \\
\text { for other trainees or that these reactions may trigger other trainees too. }\end{array}$ \\
\hline The feedback given by an external trainer make me feel more confident. \\
\hline
\end{tabular}

The other 3 types of reflections presented in Table 1 illustrate that the programme had an impact on the way the participants began to use their knowledge as they became more aware of their new skills through the continuous feedback from the mentors - either in the online group supervision sessions or in the reflective logs. There was an increasing number of specialists from the first to the last reflective logs who began to use this type of instrument to record their data and build a strong team of specialists with real-time feedback from different interventions.

\section{Conclusions}

The Erasmus+ PrECIVIM project has emphasized most of all the need to have mentors and partners with a constructive opinion and feedback. The professional development conducted in all 4 participating countries as a multicultural approach has highlighted the importance of reflecting from the MDVI child's perspective. Based on that, reflective logs should be considered part of the intervention process because they provide precious information about the communication development of an MDVI child which can only be built through a functional curriculum. The evaluation and intervention practices need to be permanently perfected and reflected upon and specialists working with MDVI children should always converts their reflections into actions.

\section{Acknowledgements}

This material was created with the financial support of the EU within the Erasmus + programme, PrEciVIM project, No: 2017-1-EL01-KA201-036289. The article reflects exclusively the authors' opinions and views, and the European Commission is not responsible for any use of the provided information. 


\section{References}

Bain, J. D., Mills, C., Ballantyne, R., Packer, J. 2002. Developing Reflection on Practice Through Journal Writing: Impacts of Variations in the Focus and Level of Feedback. Teachers and Teaching 8(2): 171-196.

Coulson, D., Harvey, M. (2013). Scaffolding student reflection for experience-based learning: A framework. Teaching in Higher Education, 18(4): 401-413. doi:10.1080/13562517.2012.752726

Darling-Hammond, L., Hyler, M. E., Gardner, M. (2017). Effective Teacher Professional Development (research brief). Palo Alto, CA: Learning Policy Institute.

Helyer, R. (2015). Learning through reflection: the critical role of reflection in work-based learning (WBL), Journal of Work-Applied Management, 7(1): 15-27. https://doi.org/10.1108/JWAM-10-2015-003

Kreber, C., Castleden, H. 2009. "Reflection on Teaching and Epistemological Structure: Reflective and Critically Reflective Process in 'pure/soft' and 'pure/hard' Fields." Higher Education 57(4), 509-531.

McCarthy, J. (2011). Reflective Writing, Higher Education and Professional Practice, Journal for Education in the Built Environment, 6:1, 29-43, DOI: 10.11120/jebe.2011.06010029

Powell, R., Vlachopoulos, P., Shaw, R. (2017). Development and Evaluation of a Reflective Log Assignment Designed to Enhance Postgraduate Psychology Students' Learning Experience. Journal of Perspectives in Applied Academic Practice. 5 (3). doi: 10.14297/jpaap.v5i3.232. available at: https://jpaap.napier.ac.uk/index.php/JPAAP/article/view/232/html

Rudiyati, S., Sukinah, S, Rahmawati, R. (2019). Requirements Need to be Fulfilled in Learning Children with Multiple Disabilities Visually Impairment. Advances in Social Science, Education and Humanities Research, vol. 296: 432-437.

Urdang, E. (2010). Awareness of self - a critical tool, Social Work Education, 29 (5): 523-538.

Walker, R., Cooke, M., Henderson, M. and Creedy, D.K., (2013). Using a critical reflection process to create an effective learning community in the workplace, Nurse Education Today, 33(5): 504-511. 